\title{
Longevidade de inflorescências de lírio, de diferentes estádios de colheita, pré-tratadas com sacarose e tiossulfato de prata (STS)
}

\author{
Longevity of lilly inflorescences harvested at different stages of development \\ and pulsed with sucrose and silver thiosulfate (STS)
}

\author{
José Geraldo Barbosa ${ }^{1}$ Andréa Rejane Santana Medeiros ${ }^{2}$ Fernando Luiz Finger ${ }^{2}$ \\ Fernando Pinheiro Reis ${ }^{2}$ Virgínia de Souza Álvares ${ }^{2}$ \\ Mauricio Soares Barbosa ${ }^{2}$
}

\section{RESUMO}

A senescência é provocada por mudanças fisiológicas e bioquímicas como degradação do amido e clorofila, aumento da respiração e produção de etileno. $O$ tratamento de flores cortadas com STS constitui uma das formas de inibir a produção ou ação do fitormônio. Para avaliar os efeitos do STS, em combinação ou não com sacarose, aplicado em solução de condicionamento, sobre a longevidade e a qualidade de inflorescências cortadas de lírio, variedade Ace, hastes com 3 botões de diferentes idades, foram tratadas com solução de sacarose $5 \%$ por 12 horas; solução de STS $1 \mathrm{mM}$ por 15 minutos; solução de STS (15 minutos) + solução de sacarose por 12 horas e controle (água destilada). Foram avaliados: comprimento e abertura dos botóes, teor relativo de água e teor de clorofila na folha e longevidade. A longevidade das inflorescências de lírio, variedade Ace, é influenciada pelos estádios de colheita, obtendo-se maior longevidade no estádio mais jovem, A. Inflorescências colhidas no estádio A apresentam maior diâmetro quando pré-tratadas com STS; todavia, este tratamento compromete a abertura dos botões e a qualidade das flores. A sacarose possibilita a abertura dos botões colhidos no estádio A e aumento da vida útil da flor. Assim, o uso de solução de sacarose, na concentração de $5 \%$ permite a colheita de inflorecências de lírio em estádio prematuro, obtendo-se maior vida de vaso da flor cortada.

Palavras-chave: Lilium longiflorum, conservação póscolheita, flor cortada.

\section{ABSTRACT}

Flower senescence is triggered by physiological changes including degradation of starch and chlorophyll, increase in respiration and ethylene production. Pulsing of cut flowers with STS is one efficient way to inhibit ethylene action and production. To evaluate the effects of STS combined or not with sucrose on flower longevity and quality, lily inflorescences $c v$. Ace were pulsed with 5\% sucrose for 12 hours, $1 \mathrm{mM}$ STS for 15 minutes, STS + sucrose and control (distilled water) in inflorescences harvested with three bud flowers at different ages. They were evaluated at length and opening of the buds, relative water content, content of chlorophyll and longevity. The longevity of lilly flowers variety Ace is influenced by the stage of harvest, with longer longevity for the younger stage, A. Inflorescences harvested at stage A and pulsed with STS had bigger diameter, but the treatment reduced the bud opening and flower quality. The sucrose improved the opening of buds harvested at stage $A$ and increased the flower vase life. Thus the use of sucrose at 5\% allowed harvesting the inflorescences at earlier stage, increasing the flower vase life.

Key words: Lilium longiflorum, postharvest, cut flower.

\section{INTRODUÇÃO}

As hastes do lírio constituem inflorescência, sendo desuniforme o desenvolvimento dos botões florais no momento da colheita e a qualidade póscolheita determinada, em parte, pelo percentual de abertura dos botões. O processo de senescência em células vegetais é provocado por uma série de mudanças fisiológicas e bioquímicas, como: aumento da atividade de enzimas, degradação de amido e clorofila, modificações nas membranas, aumento do processo respiratório, aumento da produção de etileno, perda da permeabilidade da parede celular e redução

${ }^{1}$ Departamento de Fitotecnia, Centro de Ciências Agrárias (CCA), Universidade Federal de Viçosa (UFV), 36.570.000, Viçosa, MG, Brasil. E-mail: jgeraldo@ufv.br

${ }^{2}$ Departamento de Fitotecnia, CCA, UFV, Viçosa, MG, Brasil. 
no peso da matéria fresca provocada pela perda de água (MAYAK, 1987). O aumento da vida pós-colheita de flores cortadas é extremamente importante, e pesquisas vêm sendo desenvolvidas no sentido de determinar os fatores que influenciam o desencadeamento de tais processos.

Em várias espécies, a sacarose tem sido eficiente no prolongamento da vida de vaso e promoção de abertura de botões imaturos, propiciando colheita antecipada e maior vida de vaso da flor cortada. De acordo com NOWAK \& RUDNICKI (1990), a sacarose pode ser usada nas concentrações entre 2 e $5 \%$, de acordo com a espécie estudada.

Sabe-se que, em muitas espécies, o fitormônio etileno age como importante regulador da senescência em flores (DAVIS et al., 1995). O etileno pode agir em tecidos imaturos, inibindo o seu crescimento; em órgãos maduros, atua na promoção do amadurecimento, da senescência e da abscisão de flores e frutos (REID, 1985). A resposta do tecido vegetal ao etileno é acompanhada pela indução autocatalítica do próprio hormônio, ou seja, a exposição do tecido ao etileno estimula a sua biossíntese, devido ao aumento das enzimas ACCsintase e ACCoxidase. Segundo ALTVORST \& BOVY (1995), um dos possíveis mecanismos que contribuem para a indução da biossíntese do etileno é a mudança na receptividade do tecido ou na sensibilidade ao etileno. Conforme relataram NOWAK \& RUDNICKI (1990), as flores de corte variam quanto ao grau de sensibilidade ao etileno, de acordo com a espécie estudada, sendo as liliáceas classificadas como sensíveis à sua ação. A idade das flores também é importante, já que se observa a existência de relação direta entre idade da planta e sensibilidade ao etileno, e, quanto mais velho o tecido, menores serão as concentrações de etileno necessárias para desencadear o processo de senescência (PORAT et al., 1995).

A resposta ao etileno se dá, provavelmente, pela sua ligação a um receptor específico, responsável por enviar o sinal para sua ativação. Um dos métodos utilizados com sucesso na inibição da produção ou ação do etileno é o tratamento das flores cortadas com o íon prata $\left(\mathrm{Ag}^{+}\right)$, uma vez que este atua como inibidor competitivo da ligação entre o etileno e o seu receptor (ALTVORST \& BOVY, 1995). Para flores de corte, temse dado preferência à utilização do complexo iônico tiossulfato de prata (STS), devido à sua boa mobilidade na planta e por apresentar menores problemas quanto à fitotoxidez (CAMPANHA, 1997), além de possuir efeitos germicidas (FLORACK et al., 1996). O presente trabalho teve como objetivo avaliar a longevidade de inflorescências de lírio (Lilium longiflorum), variedade Ace, colhidas em diferentes estádios de abertura de flor e condicionadas em sacarose e tiossulfato de prata.

\section{MATERIAL E MÉTODOS}

O experimento foi realizado no Laboratório de fisiologia pós-colheita do Departamento de Fitotecnia da Universidade Federal de Viçosa, em Viçosa, MG, durante o mês de outubro de 1998, sob temperatura média de $25^{\circ} \mathrm{C}, 70 \pm 10 \%$ e intensidade luminosa de $12 \pm 2 \mu \mathrm{mol} \mathrm{m} \mathrm{seg}^{-1}$. As hastes foram colhidas de plantas de lírio, variedade Ace, cultivadas sob estufa, com irrigação e padronizadas com tamanho de $55 \mathrm{~cm}$ com três botões florais, de acordo com as exigências do mercado. $\mathrm{O}$ experimento foi montado no delineamento inteiramente casualizado, com os tratamentos dispostos em arranjo fatorial $(3 \times 2 \times 2)$, nos quais se utilizaram três estádios de colheita, duas doses de sacarose $(0$ e $5 \%)$ e duas doses de tiossulfato de prata - STS $(0$ e $1 \mathrm{mM})$, com três repetições, totalizando 36 parcelas.

As inflorescências foram colhidas nos estádios A (maior botão $=7,0 \pm 1,0 \mathrm{~cm}$; menor botão $=5,0$ $\pm 1,0)$, B (maior botão $=10,0 \pm 1,0 \mathrm{~cm}$; menor botão $=6,5$ $\pm 1,0)$ e C (maior botão $=13,0 \pm 1,0 \mathrm{~cm}$; menor botão $=8,5$ $\pm 1,0 \mathrm{~cm}$ ), de acordo com o mercado, de forma se obter maior vida de vaso.

Para cada estádio de colheita, foi feita a imersão da base das hastes em: a) 5\% de sacarose por 12 horas, b) solução de STS $1 \mathrm{mM}$ por 15 minutos, c) solução de STS (15 minutos) + solução de sacarose por 12 horas e d) controle (água destilada). Após os tratamentos, as hastes foram mantidas em água destilada até o descarte das flores. O STS foi preparado de acordo com NOWARK \& RUDNICKI (1990). Foram usados recipientes de vidro com capacidade para dois litros de solução. A duração do experimento coincidiu com o descarte das inflorescências do tratamento mais eficiente.

Foram avaliadas as seguintes características: percentual de botões abertos no final do experimento, comprimento máximo do botão (determinado a partir da extremidade deste até a sua linha de união com o pedicelo) e diâmetro máximo da flor (medida máxima entre duas pétalas opostas a partir de suas extremidades). A longevidade das flores foi determinada pelo número de dias compreendido entre a colheita e a perda da qualidade da flor, caracterizada pelo surgimento de rachaduras nas pétalas e início de flacidez. Com relação à haste, o fim da longevidade ocorreu pela senescência da última flor aberta.

Procedeu-se a análise de variância, e as médias foram comparadas utilizando-se o teste de Newman-Keuls, a 5\% de significância.

Para avaliação do teor relativo de água, foi colocada em cada parcela uma haste a mais, da qual foram recolhidas amostras a cada três dias, da mesma folha. Com a utilização de um furador de $12 \mathrm{~mm}$ de 
diâmetro, foram removidos seis discos de folhas da haste. Esses discos foram pesados no início e colocados para hidratar em espuma de poliuretano, de $2 \mathrm{~cm}$ de espessura, previamente furada e umedecida com água destilada, por cerca de cinco horas, para que ocorresse a saturação das células e os pesos ficassem constantes. Os discos foram, então, pesados e colocados para secar em estufa durante 48 horas, a $70^{\circ} \mathrm{C}$, quando foram pesados novamente. $\mathrm{O}$ teor relativo de água, em percentagem, foi calculado segundo a equação, proposta por WEATHERLEY (1950), determinada pela razão entre a quantidade de água no tecido fresco (peso da matéria fresca, $\mathrm{F}$ - peso da matéria seca, W) e a quantidade de água no tecido quando este se encontrava túrgido (peso da matéria túrgida, $\mathrm{T}$ - peso da matéria seca, $\mathrm{W})$, ou seja:TRA $=(\mathrm{F}-$ W/T-W) x 100 .

Procedeu-se à análise de variância utilizando- se o delineamento inteiramente casualizado, em parcelas subdivididas, tendo nas parcelas os tratamentos ( 3 estádios x 2 percentuais de sacarose $\mathrm{x} 2$ doses de STS) e nas subparcelas, o tempo de coleta de amostras das folhas (coleta aos 0,3, 6,9 e 12 dias da montagem do experimento), com três repetições. As médias foram analisadas, utilizando-se o teste de Newman-Keuls a 5\% de significância.

A clorofila das folhas foi extraída, a cada três dias, pela trituração de $0,3 \mathrm{~g}$ de tecido fresco em $5,0 \mathrm{~mL}$ de acetona $80 \%$ e cerca de $10 \mathrm{mg}$ de $\mathrm{CaCO}_{3}$, em almofariz. O extrato foi filtrado e o seu volume completado para $25 \mathrm{~mL}$ com acetona $80 \%$. A absorbância foi determinada em espectrofotômetro a $645 \mathrm{~nm}$ e $663 \mathrm{~nm}$ de comprimento de onda (ARNON, 1949), calculado pela fórmula (clorofila $=20,2 \mathrm{~A}_{645}+8,02 \mathrm{~A}_{663} \mathrm{mg} / \mathrm{L}$ ), sendo: clorofila = concentração de clorofila; $\mathrm{A}_{645}=$ leitura obtida no espectrofotômetro a $645 \mathrm{~nm}$; e $\mathrm{A}_{663}=$ leitura obtida no espectrofotômetro a $663 \mathrm{~nm}$. Procedeuse à análise de variância à semelhança do item "teor relativo de água nas folhas".

\section{RESULTADOS E DISCUSSÃO}

Nas hastes colhidas nos estádios B e C, o percentual de abertura dos botões foi de $100 \%$. Já nas hastes colhidas no estádio A, houve abertura de todos os botões, quando se utilizou sacarose isoladamente. A imersão da base das hastes em STS, com ou sem sacarose, proporcionou $66,6 \%$ de abertura do menor botão (botão 3), enquanto a ausência de solução preservativa impossibilitou a antese deste (Tabela 1). Assim, os pré-tratamentos foram efetivos para abertura de botões jovens de lírio, o que também foi observado em botões de Rosa hibrida (L.) (REID et al., 1989),
Tabela 1 - Abertura dos botões 1, 2 e 3, em percentagem (\%), de inflorescências de lírio colhidas no estádio $\mathrm{A}^{1}$ e tratadas com soluções preservativas. Viçosa, MG, 1998.

\begin{tabular}{llll}
\hline \multirow{2}{*}{ Soluções } & \multicolumn{3}{c}{ Estádio A } \\
\cline { 2 - 4 } & Botão 1 & Botão 2 & Botão 3 \\
\hline Controle & $100 \mathrm{a}^{1 * *}$ & $100 \mathrm{a}$ & $0 \mathrm{c}$ \\
Sacarose, $5 \%$ & $100 \mathrm{a}$ & $100 \mathrm{a}$ & $100 \mathrm{a}$ \\
STS, 1mM & $100 \mathrm{a}$ & $100 \mathrm{a}$ & $66,67 \mathrm{~b}$ \\
Sacarose, $5 \%+$ STS,1mM & $100 \mathrm{a}$ & $100 \mathrm{a}$ & $66,67 \mathrm{~b}$ \\
& & & \\
\hline
\end{tabular}

${ }^{1}$ A - Menor estádio: comprimento do maior botão: 7,0 $\pm 1,0 \mathrm{~cm}$.

${ }^{2}$ Médias seguidas da mesma letra nas colunas não diferem entre si pelo teste de Newman- Keuls, a 5\% de probabilidade de erro.

Gladiolus sp. (SEREK et al., 1994) e Lilium hibrido (SONG et al., 1996), quando submetidos a prétratamentos com STS e ou, sacarose.

Quanto à qualidade, as inflorescências colhidas nos estádios A e B, ao serem tratadas com STS, apresentaram deformidades na flor, como pétalas retorcidas, ou seja, malformação da flor, atingindo cerca de $8,33 \%$ das flores do estádio B. No entanto, nesse estádio, as inflorescências tratadas com sacarose + STS não exibiram deformidades. No estádio $\mathrm{A}$, tais características ocorreram nos tratamentos contendo STS com ou sem sacarose, ocorrendo em 19,36\% das flores abertas. Apesar de ter contribuído para a abertura dos botões, o STS causou deformidades nos botões colhidos no estádio A. Já os botões colhidos no estádio $\mathrm{B}$, não apresentaram deformidades quando tratados com STS + sacarose. Possivelmente, os efeitos fitotóxicos descritos anteriormente foram causados pelo STS, evidenciando-se que, num próximo trabalho, deve ser utilizado em menores concentrações, quando os botões forem colhidos no estádio A.

Não houve efeito do STS e da sacarose sobre o comprimento máximo do botão e do diâmetro máximo da flor. No entanto, com relação aos estádios de colheita, observou-se diferença tanto no comprimento máximo do botão (Tabela 2) quanto no diâmetro máximo da flor, existindo interação significativa entre as doses de STS e de estádio, com relação a essa característica (Tabela3).

A colheita no maior estádio de abertura proporcionou maior comprimento dos botões. Houve aumento de $27,61 \%$ do estádio A para o $\mathrm{C}$, quanto ao maior botão (botão 1) e de $25,39 \%$ com relação ao botão 2 (Tabela 2).De acordo com Woltering \& Van Doorn, 
Tabela 2 - Valores médios, em centímetros, do comprimento máximo dos botões 1 e 2 de inflorescências de lírio colhidas em três estádios de desenvolvimento. Viçosa, MG, 1998

\begin{tabular}{lll}
\hline Estádio & Botão 1 & Botão 2 \\
\hline A (maior botão $7 \pm 1 \mathrm{~cm})$ & $12,82 \mathrm{c}^{1}$ & $12,29 \mathrm{c}$ \\
B (maior botão $10 \pm 1 \mathrm{~cm})$ & $14,52 \mathrm{~b}$ & $13,45 \mathrm{~b}$ \\
C (maior botão $13 \pm 1 \mathrm{~cm})$ & $16,36 \mathrm{a}$ & $15,41 \mathrm{a}$ \\
\hline
\end{tabular}

${ }^{1}$ Médias seguidas da mesma letra nas colunas não diferem entre si pelo teste de Newman- Keuls, a $5 \%$ de probabilidade de erro.

apud SEREK et al. (1994), em botões muito jovens ocorrem rápida desidratação e alta produção de etileno. Ainda, segundo SEREK et al. (1994) e HAN \& BOYLE (1996), botões florais muito jovens são abortados por falta de carboidratos, e o etileno atua possivelmente na redução do vigor desses botões, reduzindo a capacidade destes na competição por carboidratos com botões mais desenvolvidos.

De acordo com os resultados apresentados na tabela 3, observa-se que o uso de STS possibilitou maior diâmetro das flores no estádio A, indicando sua efetividade em diminuir os efeitos nocivos do etileno em botões muito jovens, aumentando a capacidade destes de absorção da solução, comprovado pelo aumento do diâmetro das flores nos estádios mais jovens, o que não se verificou nos estádios B e C. Na ausência de STS, houve diferença entre os três estádios de desenvolvimento, sendo a variação entre o maior e o menor estádio de 30,22\%, o que não ocorreu quando se usou $1 \mathrm{mM}$ de STS (Tabela 3). Observou-se que, no lírio, os benefícios do STS ocorreram principalmente nos estádios imaturos. Também, em gladíolo, MOR et al. (1981) observaram que o uso de STS proporcionou efeitos benéficos quanto ao aumento do diâmetro da flor.

A maior longevidade é influenciada diretamente pelo estádio de colheita e uso soluções que possibilitem a abertura de todas as flores, sendo de importância capital para o mercado, seja pela maior período de permanência das flores na floricultura ou pela maior vida de vaso para o consumidor final. A longevidade das flores 1 e 2 e das hastes foi influenciada pelos estádios de colheita, não havendo efeito de STS e sacarose (Tabela 4). Inflorescências colhidas no estádio A foram significativamente superiores quanto à longevidade, observando-se diferença, em relação ao estádio C, de 4,33 dias na haste e de 5,91 e 5,83 dias nas flores 1 e 2 , respectivamente.

Quanto aos aspectos qualitativos, observaram-se bons resultados no diâmetro máximo da flor (Tabela 3) quando foi utilizado STS. No entanto, esse tratamento teve menor eficiência na abertura de flores no estádio A (Tabela 1), comparado com o condicionamento apenas com sacarose, mostrando que as inflorescências de lírio podem ser colhidas no estádio A quando pré-tratadas com sacarose. Sem condicionamento, as hastes podem ser colhidas no estádio C, pois haverá $100 \%$ de abertura, bem como diâmetro satisfatório das inflorescências.

A aplicação de STS e sacarose e o estádio de colheita não afetaram o teor relativo de água. Houve efeito do tempo (dias após a colheita), sendo os valores estimados apresentados na figura 1. Foi observado declínio do teor relativo de água nas folhas até o sexto dia, sendo de 5,31\% do valor inicial. Posteriormente, observou-se aumento do teor, o que pode ser atribuído a uma redução na temperatura média de 25 para $21^{\circ} \mathrm{C}$, do sexto ao décimo segundo dia, a qual, provavelmente, acarretou redução da transpiração e menores perdas de água, o que favoreceu o aumento do TRA. Possivelmente, sob altas temperaturas a taxa de absorção de água foi menor que a transpiração nos tecidos, ocasionando redução no percentual do teor relativo de água, tendo comportamento semelhante sido observado por ICHIMURA et al. (1999) em rosas.

Não houve efeito dos tratamentos sobre o teor de clorofila, cujos teores médios foram de $0,97 \mathrm{mg}$ $\mathrm{g}^{-1}$ de matéria fresca.

Tabela 3 - Valores médios (cm) do diâmetro máximo da flor 1 e 2 de inflorescências de lírio colhidas em três estádios de desenvolvimento, em função de doses STS. Viçosa, MG, 1998.

\begin{tabular}{|c|c|c|c|c|c|c|}
\hline \multirow{3}{*}{$\begin{array}{l}\text { Dose de STS } \\
(\mathrm{mM})\end{array}$} & \multicolumn{6}{|c|}{ Estádio de Colheita } \\
\hline & \multicolumn{2}{|c|}{$\mathrm{A}^{1}$} & \multicolumn{2}{|c|}{$\mathrm{B}^{1}$} & \multicolumn{2}{|c|}{$\mathrm{C}^{1}$} \\
\hline & Flor 1 & Flor 2 & Flor 1 & Flor 2 & Flor 1 & Flor 2 \\
\hline 0 & $10,52 \mathrm{Cb}^{2}$ & $10,33 \mathrm{Bb}$ & $12,48 \mathrm{Ba}$ & $12,37 \mathrm{Aa}$ & $13,70 \mathrm{Aa}$ & $13,27 \mathrm{Aa}$ \\
\hline 1 & $12,00 \mathrm{Aa}$ & $12,07 \mathrm{Aa}$ & $12,58 \mathrm{Aa}$ & $12,75 \mathrm{Aa}$ & $13,15 \mathrm{Aa}$ & $12,82 \mathrm{Aa}$ \\
\hline
\end{tabular}

${ }^{1} \mathrm{~A}$ (maior botão $-7 \pm 1 \mathrm{~cm}$ ); B (maior botão - $10 \pm 1 \mathrm{~cm}$ ); C (maior botão $-13 \pm 1 \mathrm{~cm}$ );

${ }^{2}$ Médias seguidas de mesma letra maiúscula na mesma linha (para mesma flor) e pelo menos uma mesma letra minúscula na coluna não diferem entre si, pelo teste de Newman- Keuls, a $5 \%$ de probabilidade de erro.

Ciência Rural, v.36, n.1, jan-fev, 2006. 
Tabela 4 - Valores médios (dias) da longevidade das flores 1 e 2 e das hastes de lírio colhidas em três estádios de desenvolvimento. Viçosa, MG, 1998.

\begin{tabular}{llll}
\hline Estádio & Flor 1 & Flor 2 & Haste \\
\hline A (maior botão $7 \pm 1 \mathrm{~cm})$ & $13,33 \mathrm{~A}^{1}$ & $15,50 \mathrm{~A}$ & $17,00 \mathrm{~A}$ \\
B (maior botão $10 \pm 1 \mathrm{~cm})$ & $9,92 \mathrm{~B}$ & $12,33 \mathrm{~B}$ & $15,25 \mathrm{~B}$ \\
C (maior botão $13 \pm 1 \mathrm{~cm})$ & $7,42 \mathrm{C}$ & $9,67 \mathrm{C}$ & $12,67 \mathrm{C}$ \\
\hline
\end{tabular}

${ }^{1}$ Médias seguidas da mesma letra nas colunas não diferem entre si, pelo teste de Newman- Keuls, a 5\% de probabilidade de erro

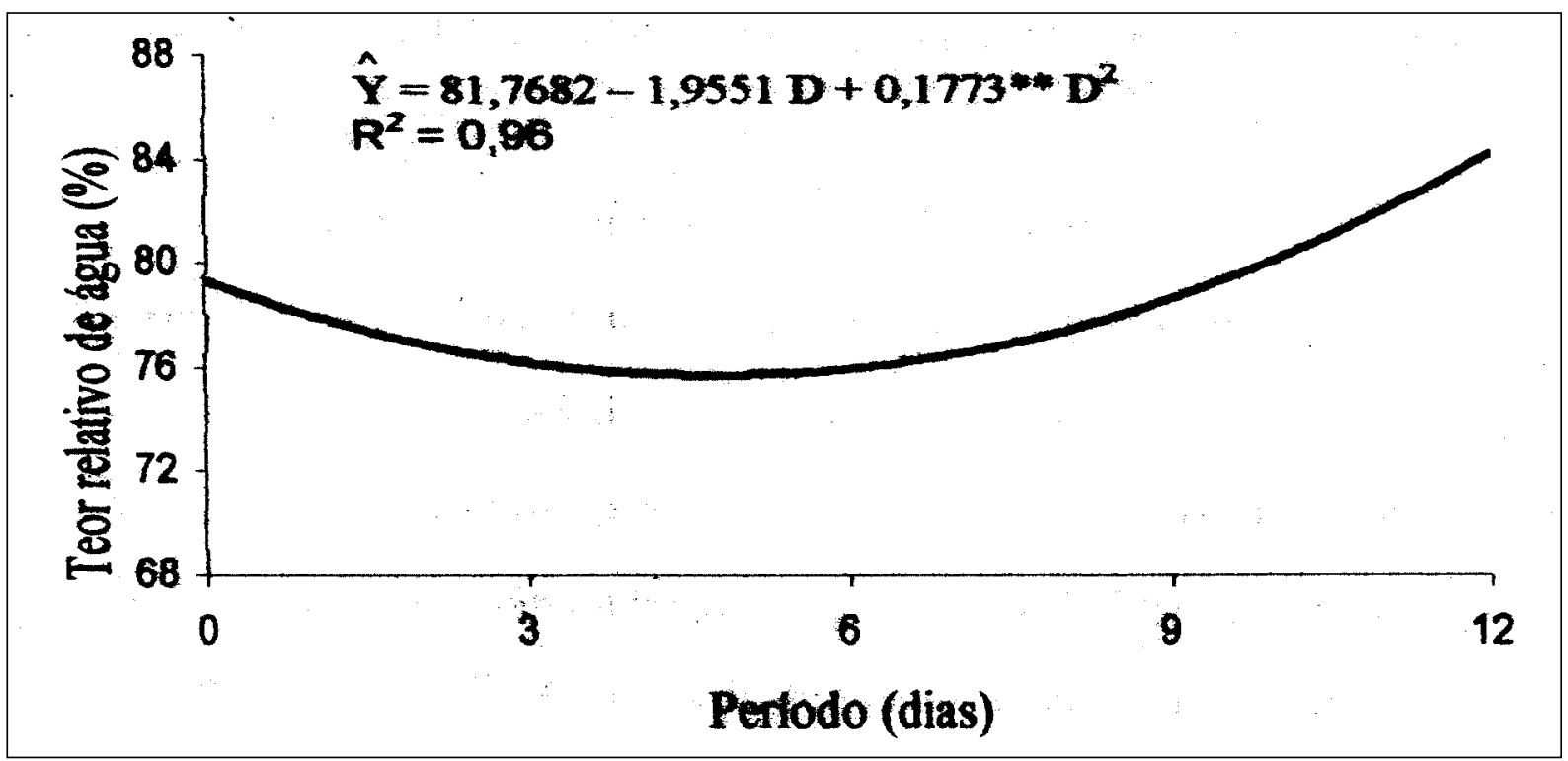

Figura 1 - Estimativa do teor relativo de água em folhas de lírio em função de dias após a colheita. Viçosa, MG, 1998.

Visualmente, no final do experimento, não se perceberam alterações na coloração das folhas que permaneceram verdes, uma vez que foram baixas as perdas de clorofila durante o experimento.

\section{CONCLUSÕES}

A longevidade das inflorescências de lírio, variedade Ace, é influenciada pelos estádios de colheita, obtendo-se maior longevidade no estádio mais jovem, A (comprimento do maior botão $=7 \mathrm{~cm}$ ), sendo a diferença entre os estádios A e C (comprimento do maior botão $=13 \mathrm{~cm}$ ) de aproximadamente cinco dias . Inflorescências colhidas no estádio A apresentam maior diâmetro quando pré-tratadas com STS; todavia, este tratamento compromete a abertura dos botões e a qualidade das flores. A sacarose possibilita a abertura dos botões colhidos no estádio A e aumento da vida útil da flor. O uso de solução de sacarose, na concentração de $5 \%$, permite a colheita de inflorecências de lírio em estádio prematuro, obtendose maior vida de vaso da flor cortada.

\section{REFERÊNCIAS}

ALTVORST, A.C.V.; BOVY, A.G. The role of ethylene in the senescence of carnation flower, a review. Plant Growth Regulation, v.16, n.1, p.43-53, 1995.

ARNON, D.I. Cooper enzyme in isolated chloroplasts: polyphenol oxidases in Beta vulgaris. Plant Physiology, v.24, n.1, p.1-15, 1949.

CAMPANHA, M.M. Manejo pós-colheita de inflorescências de ave-do-paraíso (Strelitzia reginae, Ait.). 1997. 60f. Dissertação (Mestrado em Fitotecnia) Universidade Federal de Viçosa.

DAVIS, T.D. et. al. Postharvest characteristics of cut inflorescences of Lupinus havardii. HortTechnology, v.5, n.3, p.247-249, 1995.

FLORACK, D.E.A. et. al. Toxicity of peptides to bacteria present in the vase water of cut roses. Postharvest Biology and Tecnology, v.8, n.1, p.285-291, 1996.

Ciência Rural, v.36, n.1, jan-fev, 2006. 
HAN, S.S.; BOYLE, T.B. Ethylene affects postproduction quality of easter cactus. Journal of the American Society for Horticultural Science, v.121, n.6, p.1174-1178, 1996.

ICHIMURA, K. et al. Effects of temperature, 8hidroxyquinoline sulphate and sucrose on the vase life of cut flowers. Postharvest Biology and Technology, v.15, n.1, p.33-40, 1999.

MAYAK, S. Senescence of cut flowers. HortScience, v.22, n.5, p.863-865, 1987.

MOR, Y. et. al. Effect of silver-thiosulfate pretreatment on vase life of cut standard carnations, spray carnation, and gladiolus, after a transcontinental truck shipment. HortScience, v.16, n.6, p.766-768, 1981.

NOWAK, J.; RUDNICKI, R.M. Postharvest handling and storage of cut flowers, florist greens, and potted plants. Portland: Timber, 1990. 210p.

PORAT, R. et al. 1-Methylcyclopropene inhibits ethylene action in cut phlox flowers. Postharvest Biology and Tecnology, v.6, n.4, p.313-319, 1995.
REID, M.S. Ethylene and abscission. HortScience, v.20, n.1, p.45-50, 1985 .

REID, M.S. et al. Ethylene and silver thiosulfate influence opening of cut rose flowers. Journal of the American Society for Horticultural Science, v.114, n.3, p.436-440, 1989.

SEREK, M. et al. A volatile ethylene inhibitor improves the postharvest life of potted roses. Journal of the American Society for Horticultural Science, v.119, n.13, p.572-577, 1994.

SONG, C.Y. et. al. Effects of postharvest pretreatments and preservative solution on vase life and flower quality of asiatic hybrid lily. Acta Horticulturae, v.414, n.1, p.277-285, 1996.

WEATHERLEY, P.E. Studies in the water relation of cotton plant. The field measurement of water deficits in leaves. New Phytology, v.49, n.1, p.81-97, 1950. 